\title{
Subspecific Taxonomy of Francisella tularensis McCoy and Chapin $1912 \dagger$
}

\author{
N. G. OLSUFJEV* AND I. S. MESHCHERYAKOVA
}

Tularemia Laboratory, Department of Infections in Natural Foci, The Gamaleya Institute of Epidemiology and Microbiology, Union of Soviet Socialist Republics Academy of Medical Sciences, Moscow 123098, Union of Soviet Socialist Republic's

In this note we examine the nomenclature and extend the descriptions of the subspecies of Francisella tularensis McCoy and Chapin that were proposed by Olsufjev and Meshcheryakova (J. Hyg. Epidemiol. Microbiol. Immunol. 26:291299,1982 ) but have not been validated by publication or listing in the International Journal of Systematic Bacteriology. Biochemical, pathological, ecological, and geographical characteristics are used to define three subspecies within $F$. tularensis; these are $F$. tularensis subsp. tularensis (McCoy and Chapin) subsp. nov. (type strain, GIEM Schu), F. tularensis subsp. holarctica Olsufjev and Meshcheryakova 1982, 296 (type strain, GIEM 503), and F.tularensis subsp. mediasiatica (Aikimbaev 1966) Olsufjev and Meshcheryakova 1982, 296 (type strain, GIEM 543). F. tularensis subsp. holarctica includes three biovars, I Ery's (erythromycin susceptible), II Ery (erythromycin resistant), and japonica. The now avirulent type strain of $F$.tularensis McCoy and Chapin (strain B-38 [ = ATCC 6223]) is not totally characteristic of $F$. tularensis subsp. tularensis, and that is why another type strain is proposed for this subspecies.

The infraspecific taxonomy of the causative agent of tularemia, Francisella tularensis McCoy and Chapin 1912, was published first by Olsufjev et al. in 1959 (8), as were the descriptions of two varieties, $F$. tularenis var. tularensis and $F$. tularensis var. palaearctica. Two years later, American scientists (3) supported the distinction of two kinds of the causative agent of tularemia, which differed from each other in ecological and pathogenic properties; these forms were designated forms A and B. The infraspecific taxonomy of $F$.tularensis was then supplemented by a third taxon, $F$. tularensis var. mediasiatica, by Aikimbaev in 1966 (1). These varieties are mentioned in Bergey's Manual of Determinative Bacteriology, 8th ed. (11). The International Code of Nomenclature of Bacteria (5) governs the naming of subspecies (Rule 13a); however, infrasubspecific varietal designations are not subject to the Code (Rule $14 a)$, although it does offer suggestions regarding infrasubspecific divisions (Appendix 10). Treating subspecies as taxa within a species that have several distinct and consistent features, we recognize the following as subspecies of $F$.

$\div$ The proposals in this paper were made at the meeting of the United Problem Committee for Medical Microbiology, 10 June 1981, Gorkii, Union of Soviet Socialist Republics, and at the meeting of the USSR Committee on Taxonomy and Nomenclature of Pathogenic Bacteria, Protozoa and Fungi, 24 March 1982, Moscow, Union of Soviet Socialist Republics. tularensis $(6,10):$ F. tularensis subsp. tularensis (McCoy and Chapin), the nearctic subspecies described by Olsufjev et al. in 1959 (8); $F$. tularensis subsp. holarctica, as described by Olsufjev in $1970(6)$; and $F$. tularensis subsp. mediasiatica, as described by Aikimbaev (1). Infrasubspecific distinctions are based on one or a very few features and we believe that $F$. tularensis subsp. holarctica is comprised of the following three biovars: I Ery ${ }^{\mathrm{s}}$ (erythromycin susceptible), II Ery ${ }^{\mathrm{r}}$ (erythromicin resistant) (4), and japonica (12). No transitional forms have been found among the subspecies and biovars in instances of overlapping geographic distribution. This indicates the genetic independence of the taxa. Thus, the subspecific and infrasubspecific taxonomy of $F$. tularensis includes three subspecies and three biovars.

The subspecific and infrasubspecific names given above are now widely used in the literature, but they are invalid because they have not been announced in the International Journal of Systematic Bacteriology to satisfy Rule 27 of the Bacteriological Code (5) or on the Approved Lists of Bacterial Names (14); hence, these names have no standing in bacteriological nomenclature. The purpose of this note is to validate these subspecific taxa of $F$. tularensis.

A detailed description of these taxa based on an investigation of 286 strains of $F$. tularensis has been presented recently (10). A number of 
strains were examined, including 10 strains of $F$. tularensis subsp. tularensis, 17 strains of $F$. tularensis subsp. mediasiatica, and 259 strains of $F$. tularensis subsp. holarctica (128 strains of biovar I Ery ${ }^{\mathrm{s}}, 124$ strains of biovar II Ery ${ }^{\mathrm{r}}, 6$ strains of biovar japonica, 1 strain whose biovar was not determined). The subspecific division of $F$. tularensis is based on several distinct features of the strains. These features include fermentation of glycerol, citrulline, and some carbohydrates; susceptibility to the macrolide antibiotics, as well as to lincomycin; pathogenicity for domestic rabbits and humans; ecology; geographic distribution; and some other characters, such as immunogenicity (7). In addition, we have established differences between the subspecies by estimating the contents of some fatty acids (9). The subspecies differ in some of these stable features, as well as in geographic distribution; the biovars differ in one or a very few features and, in part, geographically.

In this paper we do not give a detailed description of the genus or of the species $F$. tularensis McCoy and Chapin because these taxa have been effectively published previously $(6,9,11)$. We give here brief summaries of the characteristics of the subspecific and infrasubspecific taxa along with their type or reference strains.

Description of Francisella tularensis subsp. tularensis (McCoy and Chapin) subsp. nov. The synonyms of $F$. tularensis subsp. tularensis are the nearctic subspecies (8), kind A of Jellison et al. (3), and $F$. tularensis subsp. nearctica of Olsufjev (6). In changing the rank of this taxon from variety to subspecies (6), Olsufjev substituted the epithet nearctica for the epithet tularensis. However, this substitution infringes upon Rule 40 of the Bacteriological Code; therefore, we rehabilitate the epithet tularensis in this paper.

The morphology and principal characteristics are as described previously for the species (11). The strains of this subspecies ferment glycerol, glucose, maltose, and citrulline; they are highly susceptible to erythromycin, as well as to other macrolide antibiotics and lincomycin. This subspecies is highly pathogenic for domestic rabbits (subcutaneous infection with a single cell or a few cells is always lethal) and for humans (untreated cases of cutaneous infection have 5 to $6 \%$ mortality). Cross-immunity studies have demonstrated that animals infected with the holarctic strain are not adequately protected from the nearctic strain (7). Gas-liquid chromatography has revealed the presence of fatty acids in moderate quantities $\left(\mathrm{C}_{14: 0}, 6.5\right.$ to $\left.7.7 \%\right)$ and the presence of a higher level of $\mathrm{C}_{24: 0}$ acid (12 to $16 \%$ ) than in the holarctic subspecies (9). The antigenic substances contain more hexosamine (6 to $12 \%$ ) than they do in the holarctic subspe- cies (5 to 7\%) (13). The nearctic subspecies is found only in North America (United States, Canada) and is found more often than the holarctic subspecies (biovar I Ery").

Distribution of this causative agent of tularemia in nature is mainly by Lagomorpha and ticks.

The type strain of $F$. tularensis is strain B-38 (= ATCC 6223), but strain B-38 is completely avirulent. Hence, this strain has lost one of the most important properties of the species, and so we propose a type strain for the subspecies, strain Schu. (All type and reference strains mentioned in this paper have been deposited in the live culture museum of the Tularemia Laboratory, Gamaleya Institute of Epidemiology and Microbiology [GIEM], Academy of Medical Sciences, Moscow, Union of Soviet Socialist Republics [USSR].) This strain was isolated in 1941 in the United States by Foshay from humans. It is highly virulent and is used in many laboratories throughout the world.

Description of Francisella tularensis subsp. holarctica Olsufjev and Meshcheryakova 1982, 296. The synonyms of $F$. tularensis subsp. holarctica (hol.arc'ti.ca. Gr. prep. holos whole; Gr.n. arctos the great and little bear constellations [hence, the northern regions]; M.L. adj. holarctica generally distributed in the arctic regions) are $F$. tularensis var. palaearctica of Olsufjev et al. (8) and kind B of Jellison et al. (3). Later, because of critical remarks in the literature claiming that the terms were inexact (2) and on the basis of geographical distribution, it was proposed that this taxon be named $F$. tularensis subsp. holarctica $(6,10)$.

The morphology and principal characteristics are as described previously for the species (11). The strains of this subspecies are characterized by the capacity to ferment glucose and maltose but not citrulline and glycerol (biovar japonica is an exception). This subspecies is moderately pathogenic for domestic rabbits (lethal dose by subcutaneous inoculation, $10^{8}$ to $10^{9}$ cells). Untreated cutaneous infections with this subspecies in humans are lethal in less than $0.5 \%$ of the cases. The holarctic subspecies has been found to contain a greater quantity of $\mathrm{C}_{14: 0}$ fatty acid ( 9 to $11 \%$ ) and a lower quantity of $\mathrm{C}_{24: 0}$ acid (7 to $11 \%$ ) than the other subspecies, as determined by gas-liquid chromatography (9). The immunization of laboratory animals with the holarctic subspecies confers less effective protection against infection by the nearctic strain (7). F. tularensis subsp. holarctica has the greatest geographical distribution of the recognized subspecies and occurs in Europe, Asia, and North America.

Distribution of this causative agent of tularemia in nature is mediated mainly by Rodentia 
and Lagomorpha, as well as by ticks and water.

We propose strain GIEM 503 as the type strain; this strain was isolated from the tick Dermacentor pictus Herm. by N. G. Olsufjev in 1949 in the Moscow region, USSR.

The strains of the holarctic subspecies show some features which serve as the basis for infrasubspecific classification into three biovars. F. tularensis subsp. holarctica biovar I Ery (erythromycin susceptible) possesses the principal properties of the holarctic subspecies. It is highly susceptible to minimum doses of erythromycin and other macrolide antibiotics (i.e., it does not grow in the presence of more than 10 to $25 \mu \mathrm{g} / \mathrm{ml}$ ), as well as lincomycin. This biovar has been isolated in the western and northern regions of Europe, in northern and eastern Siberia, in the Far East, in some parts of central Europe (USSR), and in Kazakhstan (4). It is found in North America (United States, Canada), but less often than $F$. tularensis subsp. tularensis. Reference strain GIEM c/a7 was isolated from humans by V. F. Sjaduk in 1976 in the Moscow region, USSR. F. tularensis subsp. holarctica biovar II Ery (erythromycin resistant) is resistant to considerable concentrations of erythromycin and other macrolide antibiotics, as well as to lincomycin (it grows in medium containing 3,200 to $6,400 \mu \mathrm{g}$ of antiobiotic per $\mathrm{ml}$ ) (4). This biovar is found only in Eurasia, in central and eastern Europe, and in the Caucasus and is predominant in western Siberia and Kazakhstan (4). Reference strain GIEM 503 is also the type strain of the subspecies. F. tularensis subsp. holarctica biovar japonica, which was described originally by Rodionova (12), differs from the other biovars in the ability to ferment glycerol. This biovar is distributed on the Japanese islands, where the other biovars are not found. Biovar japonica is susceptible to erythromycin, like biovar I Ery'. Reference strain GIEM Miura was isolated from humans by Ohara in 1975 .

Francisella tularensis subsp. mediasiatica (Aikimbaev) Olsufjev and Meshcheryakova 1982, 296. F. tularensis subsp. mediasiatica (med.i.as.i.at'i.ca. Gr. adj. media middle; Gr. adj. asiatica asian; Gr. M. L. adj. mediasiatica pertaining to mid-Asia) was originally described by Aikimbaev (1) and was found in the middle Asian region of the USSR. The morphology and principle characteristics of this subspecies are in accord with the species description (11). This subspecies ferments glycerol and citrulline but shows weak fermentation of glucose and maltose, which is revealed by the Rodionova method (based on a determination of dehydrogenases). This subspecies is highly susceptible to erythromycin and other macrolide antibiotics and to lincomycin. Like the holarctic subspecies, it is moderately pathogenic for domestic rabbits and humans. A study of fatty acid composition has revealed the lowest quantity of $\mathrm{C}_{14: 0}$ acid (4.2 to $4.5 \%)$ and, like the nearctic subspecies, the highest quantity of $\mathrm{C}_{24: 0}$ acid (12 to $16 \%$ ), as determined by gas-liquid chromatography. It is distributed only in central asian USSR (in the deltas and valleys of the Amu-Darya, Ili, and Tshu rivers).

Distribution of this causative agent of tularemia in nature is mediated mostly by Lepus and Gerbillinae, as well as by ticks.

The type strain, strain GIEM 543, was isolated from Pallasiomys meridianus Pall. by G. M. Kunitsa in 1965 in the Alma-Ata region, USSR.

\section{LITERATURE CITED}

1. Aikimbaev, M. A. 1966 . Taxonomy of Genus Francisella. Rep. Acad. Sci. Kaz. SSR Ser. Biol. 5:42.44. (In Russian.)

2. Bell, J. F. 1965. Ecology of tularemia in North America. J. Jinsen Med. 11:33-44.

3. Jellison, W. L., C. R. Owen, J. F. Bell, and G. M. Kohls. 1961. Tularemia and animal populations. Ecol. Epizoot. Wildl. Dis. 17:1-15.

4. Kudelina, R. I., and N. G. Olsufjev. 1980. Sensitivity to macrolide antibiotics and lincomycin in Francisella tularensis holarctica. J. Hyg. Epidemiol. Microbiol. Immunol. 24:84-91

5. Lapage, S. P., P. H. A. Sneath, E. F. Lessel, V. B. D. Skerman, H. P. R. Seeliger, and W. A. Clark (ed.). 1975. International code of nomenclature of bacteria. $1975 \mathrm{Revi-}$ sion. American Society for Microbiology, Washington, D.C

6. Olsufjev, N. G. 1970. Taxonomy and characteristics of the genus Francisella Dorofeev, 1947. J. Hyg. Edpidemiol. Microbiol. Immunol. 14:67-74.

7. Olsufjev, N. G., and O. S. Emelyanova. 1963. Immunological relationships between Old and New World varieties of tularemic bacteria. J. Hyg. Epidemiol. Microbiol. Immunol. 7:178-187.

8. Olsufjev, N. G., O. S. Emelyanova, and T. N. Dunaeva. 1959. Comparative study of strains of B. tularense in the Old and New World and their taxonomy. J. Hyg. Epidemiol. Microbiol. Immunol. 3:138-149.

9. Olsufjev, N. G., and I. S. Meshcheryakova. 1982. On taxonomy of the tularemia causative agent, p. 66-71. In Blokhina et al. (ed.), Biochemistry and biophysics of microrganisms. Yozkii State University, Gorkii. (In Russian.)

10. Olsufjev, N. G., and 1. S. Meshcheryakova. 1982. Infraspecific taxonomy of tularemia agent Francisella tularensis McCoy and Chapin. J. Hyg. Epidemiol. Microbiol. Immunol. 26:291-299.

11. Owen, C. R. 1974. Genus Francisella Dorofe'ev 1947, 176, p. 283-285. In R. E. Buchanan and N. E. Gibbons (ed.), Bergey's manual of determinative bacteriology. 8th ed. The Williams \& Wilkins Co., Baltimore.

12. Rodionova, I. V. 1967. The respiration of the geographical varieties of Francisella tularensis in the presence of glycerol. Zh. Mikrobiol. Epidemiol. Immunobiol. 5:2125. (In Russian.)

13. Rodionova, I. V., and G. K. Shipitsina. 1967. The immunochemical characteristics of two geographical varieties of Francisella tularensis. Zh. Biokhim. 32:1161-1168. (In Russian.)

14. Skerman, V. B. D., V. McGowan, and P. H. A. Sneath (ed.) 1980. Approved lists of bacterial names. Int. J. Syst. Bacteriol. 30:225-420. 